\title{
MINERALOGIA DE SOLOS DAS SÊRIES ANHUMAS, CRUZ ALTA E IBITIRUNA *
}

Arary Marconi

\section{RESUMO}

\begin{abstract}
No presente trabalho, estudam-se granulometria, composição mineralógica e arredondamento das séries de solos Anhumas, Cruz Alta e Ibitiruna, no município de Piracicaba, SP, nas fracóes areia fina $(250$ a $105 \%)$ e areia muito fina $(105$ a $53 \mathrm{u})$. O material constituinte desses solos $\epsilon$ bem selecionado, predominando as fracões areia e areia muito fina, em quantidade superior a $70 \%$ dos perfis. A composição mineralógica mostra a presença de minerais estáveis, turmalina magnetita, ilmenita, estaurolita e zicornita, com ocorrência ainda de rutilo. na areia muito fina. O arredondamento é alto, exibindo os perfis grânulos arredondados, que devem ter participação de mais de um ciclo de sedimentação.

Os resultados obtidos permitem concluir que as três séries são constituídas de material de mesma origem, bem selecionado e de elevada maturidade, sendo impossivel a caracterização individual de cada série, através dos eśtudos realizados. E possível concluir, também, que o arenito Botucatu é a rocha de origem desses solos.
\end{abstract}

\section{INTRODUÇAOO}

Um dos objetivos principais da mineralogia de solos é a caracterização qualitativa e quantitativa de suas frações mais grosseiras. Os minerais constituintes dessas frações exibem um conjunto de caracteres, cujo conhecimento é da maior importância na identificação dos solos e na elucidação de sua gênes. $O$ estudo desses minerais concentra-se, em especial nas frações areia dos solos, assumindo papel de máxima importância o conhecimento do resíduo pesado.

A importância da mineralogia no estudo de solos foi primeiramente reconhecida por McGaughey e Fly (JEFFRIES, 1937) quando, em 1913, concluiram que a composição mineralógica varia com a região de ocorrência do solo.

Desde então, grande número de trabalhos tem sido publicado sobre o assunto. No Brasil, a caracterização de minerais pesados é muito frequente

* Entregue para publicação em 5/11/1973.

** Departamento de Solos e Geologia da ESALQ. 
em rochas sedimentares, porém, em solos sua utilização é ainda muito restrita.

A COMISSÃO DE SOLOS do C. N. E. P. A. (1960), realizando o levantamento de solos do Estado de São Paulo, estuda diversos perfis na região de Piracicaba, um dos quais de solo do arenito Botucatu. Para este, encontra 99 a $100 \%$ de quartzo na areia fina, além de traços de ilmenita, turmalina, estaurolita, magnetita, biotita, silimanita e apatita. Outros solos da mesma formação, situados em várias regiões do estado, apresentam resultados semelhantes aos do perfil referido.

MELFI, GRARDI e MONIZ (1966) estudam minerais pesados de solos da região de Campinas, $\mathrm{SP}$, originados de diabásio e de sedimentos glaciais. Com os resultados obtidos, os autores filiam as séries de solos às rochas da região.

A formação Botucatu foi estudada, no Estado de São Paulo, por diversos autores, merecendo destaque os trabalhos de ALMEIDA e BARBOSA (1953) e MEZZALIRA (1965) na região de Piracicaba, CARVALHO (1954) e ALMEIDA (1954) em outras regiões. Esses trabalhos mostram ser a formação Botucatu constituída de arenitos finos, com predominância de areia média a areia muito fina, grânulos arredondados e composição mineralógica simples, predominando minerais de alta estabilidade.

No presente trabalho, são estudados granulometria, composição mineralógica e arredondamento de ângulos de três séries de solos, Anhumas, Cruz Alta e Ibitiruna, situadas sobre a formação Botucatu, no município de Piracicaba, SP, procurando, com os resultados obtidos, contribuir para a caracterização e elucidação da gênese desses solos.

\section{MATERIAL E MÉTODOS}

\section{Material}

\section{Solos:}

São estudadas as frações areia fina (250 a $105 \mu)$ e areia muito fina (105 a $53 \mu$ ) dos perfis modais das séries Anhumas, Cruz Alta e Ibitiruna, no município de Piracicaba, SP. Esses solos foram classificados e descritos detalhadamente por RANZANI, FREIRE e KINJO (1966), de modo que no presente trabalho são apresentados apenas a localização dos perfis amostrados e um quadro comparativo das características gerais de cada série.

$O$ perfil modal da série Anhumas localiza-se no bairro Buracão, a $7,3 \mathrm{~km}$ da estrada Piracicaba-Botucatu, na estrada Ibitiruna-Anhumas, na altitude de $500 \mathrm{~m}$; o da série Cruz Alta, na estrada para o bairro de Cruz Ata, a 3 $\mathrm{km}$ da encruzilhada com a estrada Piracicaba-Conchas, na altitude de $590 \mathrm{~m}$; o da série Ibitiruna, na estrada que liga este bairro ao bairro dos Pintos, $500 \mathrm{~m}$ após o ribeirão dos Patos, na altitude de $550 \mathrm{~m}$. 
Quadro 1 - Caractcrísticas gerais das sêries estudadas, segundo RANZANI, FREIRE e KINJO (1966).

\begin{tabular}{llll}
\hline & \multicolumn{1}{c}{ Anhumas } & \multicolumn{1}{c}{ Cruz Alta } & \multicolumn{1}{c}{ Ibitiruna } \\
\hline grande grupo & podsólico & podsólico & podsólico \\
área do município & $14,0 \%$ & $7,3 \%$ & $4,5 \%$ \\
textura & muito grosseira & grosseira & grosseira \\
profundidade $(\mathrm{cm})$ & 50 a 75 & 50 a 75 & 100 a 150 \\
cor & parda & pardo amarelado & pardo avermelhado \\
drenagem & boa & pobre & boa \\
relêvo & forte/e ondulado & suave/e ondulado & ondulado \\
\hline
\end{tabular}

\section{Peneiras e Instrumental ótico:}

Para a análise mecânica e separação das frações areia fina e areia muito fina, utilizou-se um jogo de peneiras US Standard, com peneiras números 18, $35,60,140$ e 270 , de malhas $1000,500,250,105$ e $53 \mu$, respectivamente.

$\mathrm{Na}$ caracterização ótica dos minerais, foi utilizado microscópio $\mathrm{E}$. Leitz, modelo Standard. O aumento empregado na identificação e contagem de minerais e na determinação do arredondamento foi de $80 x$. Sempre que necessário, foi utilizada na identificação de minerais, a platina universal de Fedorov, com cinco eixos.

\section{Métodos}

\section{Amostragem:}

De cada série, retirou-se um monolito do perfil modal, delimitando-se anteriormente os horizontes dos solos. Nos monolitos, foi obtida, de cada horizonte, uma amostra inicial de cerca de $1 \mathrm{~kg}$, representativa do horizonte, evitando-se, sempre, as zonas de transição. Desta amostra inicial, depois de convenientemente misturada e sêca ao ar, foram separados 100 g que sofreram os tratamentos necessários e utilizados, a seguir, na análise minera- 
lógica. Para a análise mecânica, nova amostra foi obtida, a partir da amostra inicial de $1 \mathrm{~kg}$.

\section{Preparo das amostras:}

A eliminação de matéria orgânica foi realizada empregando-se $\mathrm{H}_{2} \mathrm{O}_{2}$ a $30 \%$, conforme técnica descrita por JEFFRIES e JACKSON (1949).

Para remoção de óxidos de ferro livres, adotou-se o método da fita de magnésio-ácido oxálico, recomendado por JEFFRIES e JACKSON (1949), que provoca a redução de $\mathrm{Fe}^{3}+$ a $\mathrm{Fe}^{2}+$, por meio de hidrogênio nascente. $\mathrm{O}$ emprego de $\mathrm{HC1}$, recomendado por vários autores, foi evitado devido ao ataque deste ácido aos minerais.

\section{Separação do resíduo pesado e montagem de lâminas:}

De cada fração de areia, $10 \mathrm{~g}$ foram utilizados para estudo da composição mineralógica e arredondamento. O resíduo pesado foi separado por meio de bromofórmio, de densidade 2.85, em funis separadores, conforme técnica já consagrada e descrita por KRUMBEIN e PETTIJOHN (1938), TWENHOFEL e TYLER (1941) e outros.

O resíduo pesado foi montado em lâminas, utilizando-se bálsamo do Canadá, artificial, de índice de refração 1,54 .

\section{Análise mecânica:}

A análise mecânica foi executada de acordo com a recomendação de KILMER e ALEXANDER (1949), utilizando $\mathrm{NaOH}, \mathrm{IN}$, como agente dispersante.

\section{Composição mineralógica:}

A composição mineralógica do resíduo pesado foi determinada microscópicamente, caracterizando-se cerca de $50 \%$ dos grânulos existentes nas lâminas. Não houve preocupação de contagem de um número fixo de minerais por horizonte, porém, em todas as amostras, esse número foi sempre superior a 500 grânulos.

Devido às dificuldades que apresentam para caracterização, os minerais opacos foram contados em conjunto.

\section{Arredondamento:}

Adotou-se a técnica de comparação visual dos grânulos observados no microscópio, com uma carta de arredondamento construída por KRUMBEIN (1941), técnica esta utilizada por vários autores, como AMARAL (1955), ROSENFELD e GRIFFTHS (1953), etc. A vantagem deste método é a rapidez na determinação do grau de arredondamento dos granulos. Em cada horizonte, determinou-se o arredondamento de 50 grânulos, da fração leve das areias estudadas. 


\section{RESULTADOS E DISCUSSÃO}

Análise mecânica

Quadro 2 - Resultados da análise mecânica das séries Anhumas, Cruz Alta e Ibitiruna (em\%).

\begin{tabular}{c|c|c|c|c|c|c|c|c}
\hline $\begin{array}{c}\text { Horizon- } \\
\text { tes }\end{array}$ & $\begin{array}{c}\text { Prof. } \\
(\mathrm{cm})\end{array}$ & \multicolumn{5}{|c|}{ areia } & muito \\
\cline { 2 - 5 } & grossa & grossa & média & fina & $\begin{array}{c}\text { muito } \\
\text { fina }\end{array}$ & silte & argila \\
\hline
\end{tabular}

Série Anhumas

$\begin{array}{lrrrrrrrr}\text { Ap } & 0 & - & 0,13 & 7,90 & 36,30 & 35,71 & 5,47 & 14,50 \\ \text { B/C } & 45 & - & 0,11 & 7,05 & 33,83 & 34,48 & 7,48 & 17,05 \\ \text { C/R } & 60 & - & 0,17 & 7,10 & 33,79 & 24,79 & 17,00 & 17,15\end{array}$

\section{Série Cruz Alta}

$\begin{array}{lrrrrrrrr}\text { Ap } & 0 & - & 0,08 & 8,75 & 41,35 & 33,02 & 4,65 & 12,15 \\ \text { A }_{3} / B_{1} & 30 & - & 0,05 & 10,29 & 37,00 & 32,18 & 5,29 & 15,20 \\ \text { C }_{\text {I }} & 60 & - & 0,09 & 9,73 & 34,32 & 30,80 & 3,60 & 21,45 \\ \text { C }_{\text {II }} & 80 & - & 0,11 & 9,41 & 33,19 & 30,75 & 5,33 & 21,20 \\ \text { C }_{\text {III }} & 110 & - & 0,14 & 9,45 & 32,97 & 32,35 & 4,89 & 20,20\end{array}$

\section{Série Ibitiruna}

$\begin{array}{lrrrrrrrr}\text { Ap } & 0 & - & 0,19 & 9,25 & 48,47 & 28,23 & 3,46 & 10,40 \\ \text { A }_{2} & 15 & - & 0,23 & 12,53 & 49,54 & 29,69 & 2,12 & 6,35 \\ \text { B }_{21} & 30 & - & 0,29 & 11,09 & 36,22 & 24,19 & 3,31 & 24,90 \\ \text { B }_{22} & 55 & - & 0,42 & 12,85 & 35,22 & 26,01 & 1,20 & 24,30 \\ \text { B } & 110 & - & 0,32 & 16,28 & 32,80 & 23,43 & 5,32 & 21,85 \\ \text { C } & 160 & - & 0,41 & 24,40 & 30,14 & 18,90 & 8,65 & 17,50\end{array}$


Os solos estudados possuem composição granulométrica muito semelhante à formação Botucatu, que, segundo ALMEIDA (1954), é um arenito bem selecionado, com grânulos de diâmetro inferior a $1 \mathrm{~mm}$, constituindo $90 \%$ da rocha. Os resultados obtidos no presente trabalho mostram que os solos em questão são constituídos de material bem selecionado, com grânulos de diâmetro inferior a $0,5 \mathrm{~mm}$, mais de $70 \%$ pertencendo a classe textural areia. Nesta classe a predominância de areia fina e areia muito fina é geral.

As curvas acumulativas das figuras 1,2 e 3 mostram serem os horizontes das três séries, bastante uniformes em sua granulometria. Como era de se esperar, uma vez que os solos são podsólicos (RANZANI, FREIRE e KINJO, 1966), os horizontes superiores são mais pobres em argila, acumulando, em consequência, maior quantidade de areia.

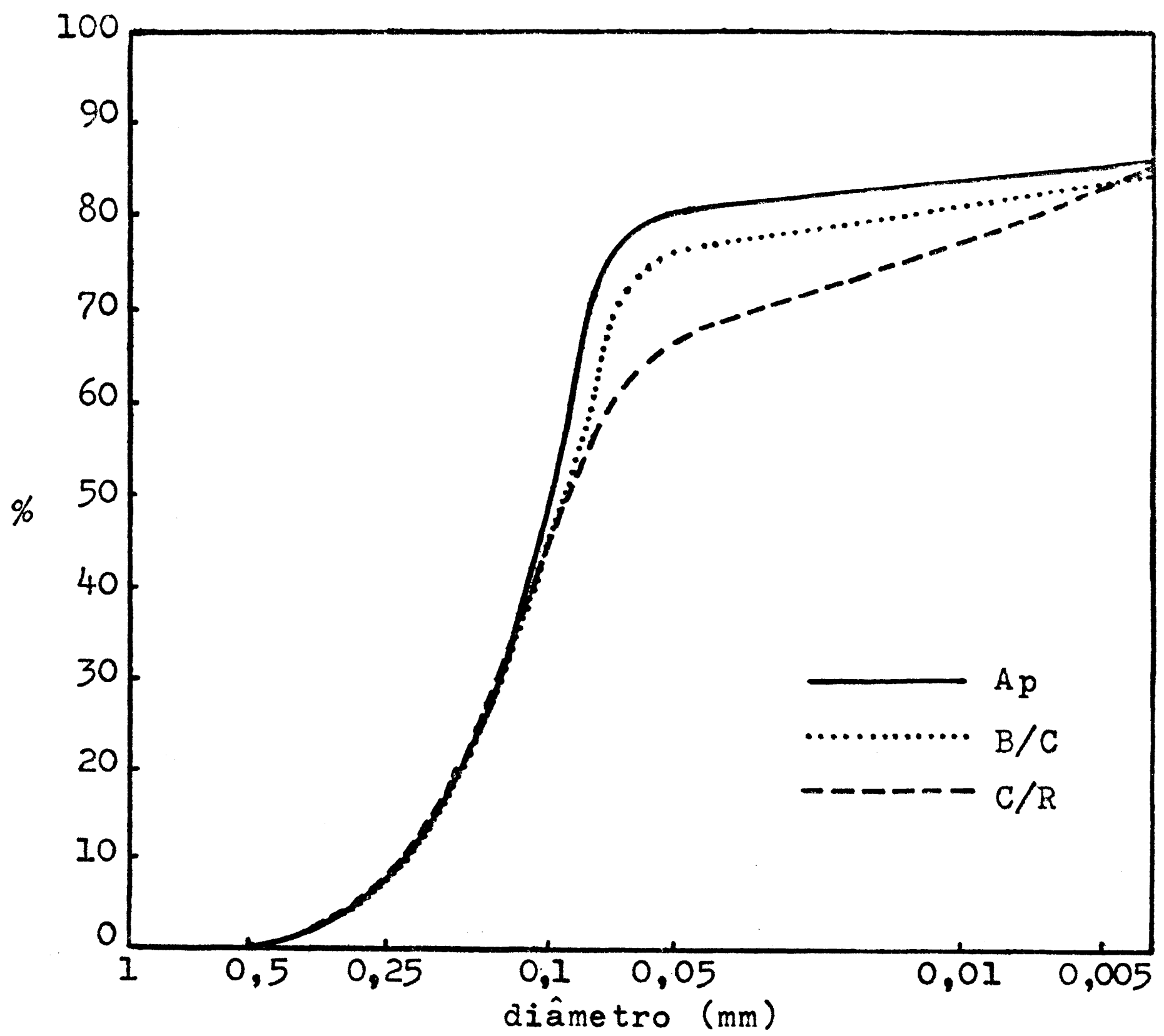

FIG. 1 - Curvas acumulativas dos horizontes da série Anhumas. 


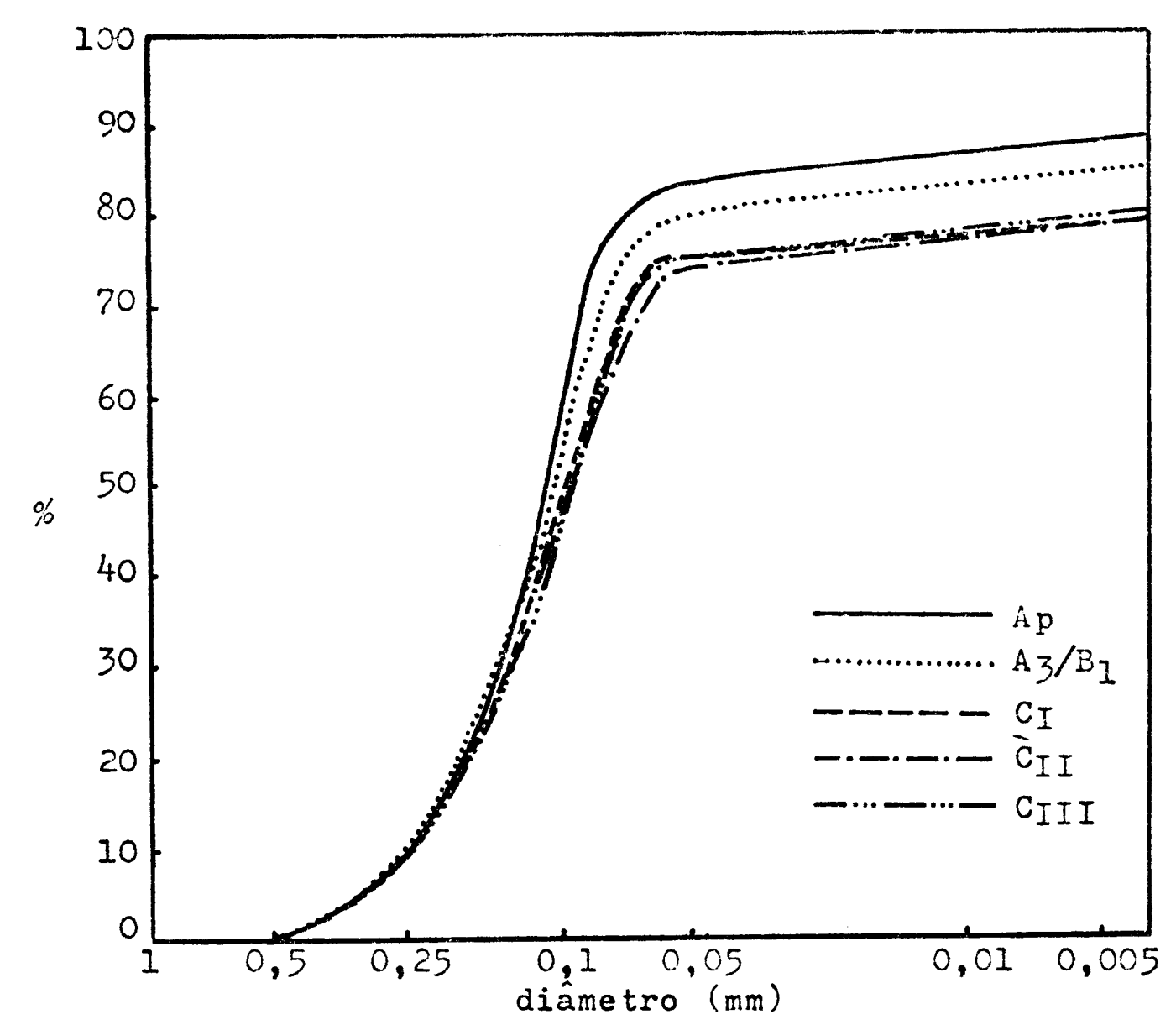

FIG. 2 - Curvas acumulativas dos horizontes da série Cruz Alta.

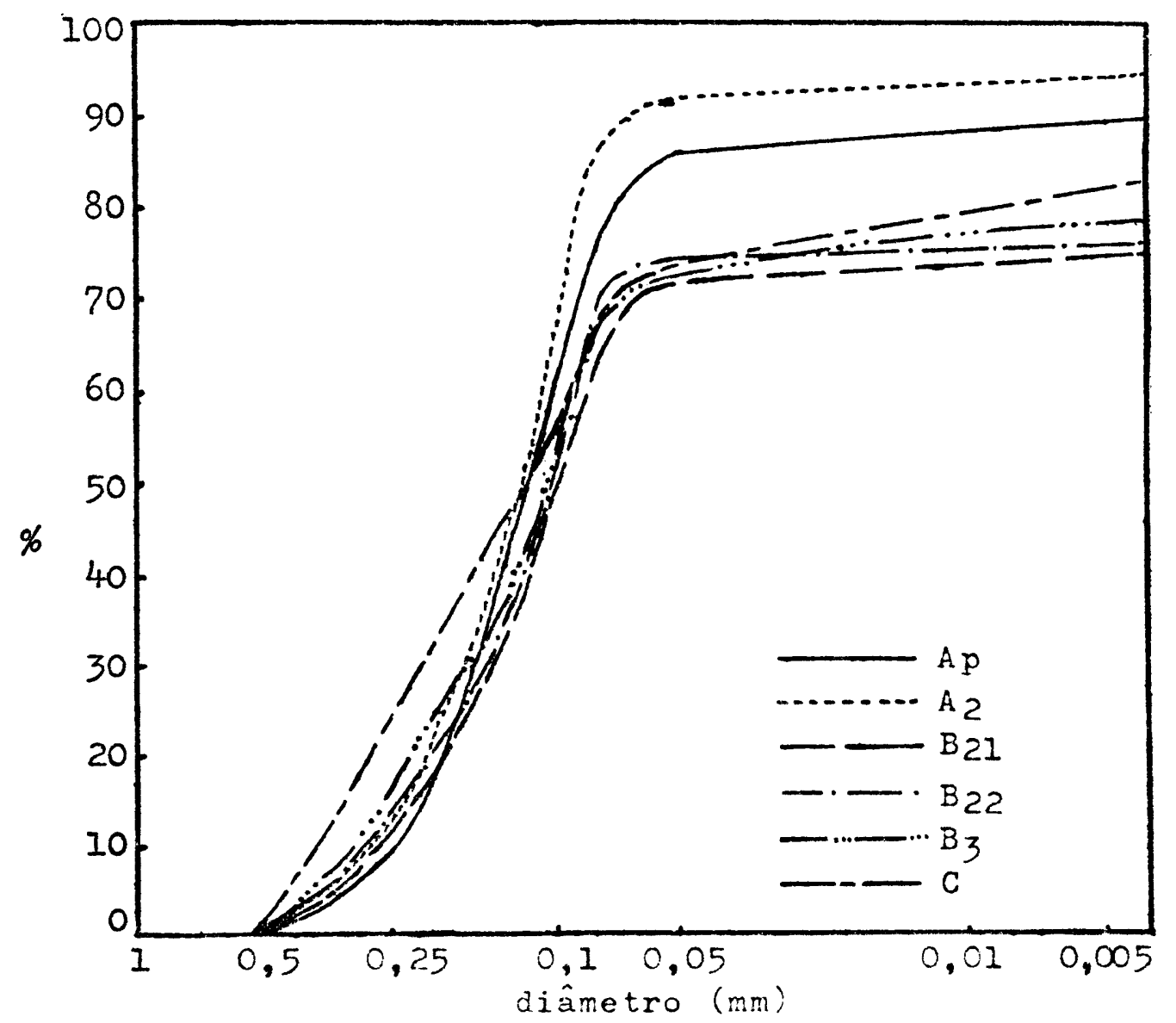

FIG. 3 - Curvas acumulativas dos horizontes da série Ibitiruna. 


\section{Composição mineralógica}

Quadro 3 - Série Anhumas: composição mineralógica do resíduo pesado da areia fina.

\begin{tabular}{|c|c|c|c|c|c|c|}
\hline \multirow[t]{2}{*}{ Minerais } & \multicolumn{2}{|c|}{$\mathrm{Ap}$} & \multicolumn{2}{|c|}{$\mathrm{B} / \mathrm{C}$} & \multicolumn{2}{|c|}{$\mathrm{C} / \mathrm{R}$} \\
\hline & freq. & $\%$ & freq. & $\%$ & freq. & $\%$ \\
\hline estaurolita & 401 & 37,0 & 375 & 36,6 & 305 & 38,2 \\
\hline min. opacos & 283 & 26,1 & 263 & 25,7 & 193 & 24,2 \\
\hline turmalina & 307 & 28,3 & 292 & 28,5 & 236 & 29,6 \\
\hline zirconita & 77 & 7,1 & 81 & 7,9 & 51 & 6,4 \\
\hline rutilo & 4 & & 2 & & 2 & \\
\hline epídoto & 9 & & 6 & & 5 & \\
\hline granada & 3 & 1,6 & 2 & 1,3 & 2 & 1,6 \\
\hline hornblenda & - & & - & & 2 & \\
\hline muscovita & 1 & & 2 & & 2 & \\
\hline titanita & - & & 1 & & - & \\
\hline Total & 1.085 & & 1.024 & & 798 & \\
\hline
\end{tabular}


Quadro 4 - Série Anhumas: composição mineralógica do resíduo pesado da arxia muito fina.

\begin{tabular}{lrrrrrr}
\hline \multicolumn{1}{c}{ Minerais } & \multicolumn{2}{c}{ Ap } & \multicolumn{2}{c}{ B/C } & \multicolumn{2}{c}{ C/R } \\
& freq. & \% & freq. & $\%$ & freq. & $\%$ \\
\hline estaurolita & 38 & 4,3 & 27 & 3,2 & 43 & 3,6 \\
min. opacos & 485 & 54,6 & 475 & 55,4 & 619 & 52,0 \\
turmalina & 80 & 9,0 & 92 & 10,7 & 113 & 9,5 \\
zirconita & 242 & 27,3 & 235 & 27,4 & 344 & 28,9 \\
rutilo & 35 & 3,9 & 26 & 3,0 & 59 & 5,0 \\
cianita & 2 & & - & & - & \\
epidoto & 6 & 0,9 & 3 & 0,4 & 10 & 1,0 \\
granada & - & & - & & 1 & \\
muscovita & - & & - & & 1 & \\
\hline Total & 888 & & & & & \\
\hline
\end{tabular}

Quadro 5 - Série Cruz Alta: composição mineralógica do resíduo pesado da areia fina.

\begin{tabular}{lrrrrrrrrrrr}
\hline & \multicolumn{3}{c}{ Ap } & \multicolumn{2}{c}{$\mathrm{A}_{3} / \mathrm{B}_{1}$} & \multicolumn{2}{c}{$\mathrm{C}_{\mathrm{I}}$} & \multicolumn{3}{c}{$\mathrm{C}_{\mathrm{II}}$} & \multicolumn{2}{c}{$\mathrm{C}_{\mathrm{III}}$} \\
min. & freq. & $\%$ & freq. & $\%$ & freq. & $\%$ & freq. & $\%$ & freq. & $\%$ \\
\hline es & 484 & 38,2 & 621 & 36,2 & 306 & 35,0 & 515 & 38,2 & 449 & 44,2 \\
m. op & 362 & 28,6 & 510 & 29,7 & 257 & 29,4 & 374 & 27,7 & 306 & 30,1 \\
tu & 350 & 27,6 & 508 & 29,6 & 271 & 31,0 & 404 & 29,9 & 213 & 20,9 \\
zi & 66 & 5,2 & 70 & 4,1 & 31 & 3,5 & 53 & 3,9 & 41 & 4,0 \\
ru & 1 & & 2 & & 1 & & 1 & & 2 & \\
ci & 2 & & 2 & & - & & - & & 1 & \\
du & - & & - & & - & & - & & 1 & \\
ep & - & 0,5 & - & 0,4 & 1 & 1,1 & - & 0,3 & 1 & 0,8 \\
gr & 2 & & 1 & & - & & - & & 3 & \\
ho & - & & - & & 4 & & - & & - & \\
mu & - & & 2 & & 2 & & 1 & & - & \\
si & 1 & & - & & 2 & & 1 & & - & \\
\hline Totai & 1263 & & 1716 & & 875 & & 1350 & & 1017 & \\
\hline
\end{tabular}


Quadro 6 - Série Cruz Alta: composiçĩo minera ógica do resíduo pesado da areia muito fina.

\begin{tabular}{lrrrrrrrrrr}
\hline mir. & \multicolumn{2}{c}{ Ap } & \multicolumn{2}{c}{$\mathrm{A}_{3} / \mathrm{B}_{1}$} & \multicolumn{2}{c}{$\mathrm{C}_{\mathrm{I}}$} & \multicolumn{2}{c}{$\mathrm{C}_{\mathrm{II}}$} & \multicolumn{3}{c}{$\mathrm{C}_{\mathrm{III}}$} \\
& freq. & $\%$ & freq. & $\%$ & freq. & $\%$ & freq. & $\%$ & freq. & $\%$ \\
\hline es & 35 & 4,1 & 30 & 3,4 & 36 & 4,2 & 33 & 3,5 & 27 & 3,2 \\
m. op & 586 & 67,9 & 540 & 61,0 & 492 & 56,8 & 559 & 58,9 & 504 & 59,6 \\
tu & 62 & 7,2 & 70 & 7,9 & 69 & 8,0 & 65 & 6,9 & 57 & 6,7 \\
zi & 160 & 18,5 & 213 & 24,1 & 216 & 24,9 & 235 & 24,8 & 222 & 26,2 \\
ru & 20 & 2,3 & 31 & 3,5 & 50 & 5,8 & 55 & 5,8 & 34 & 4,0 \\
ci & - & & - & & 1 & & - & & - & \\
ep & - & & - & & 1 & & 1 & & 2 & \\
gr & - & 0,0 & - & 0,1 & 1 & 0,3 & - & 0,2 & - & 0,3 \\
ti & - & & 1 & & - & - & - & - & \\
si & - & & - & & - & & 1 & & - & \\
\hline Total & 863 & & 885 & & 866 & & 949 & & 846 & \\
\hline
\end{tabular}

Quadro 7 - Série Ibitiruna: composição mineralógica do resíduo pesado da areia fina.

\begin{tabular}{|c|c|c|c|c|c|c|c|c|c|c|c|c|}
\hline \multirow[t]{2}{*}{ Min. } & \multicolumn{2}{|c|}{ Ap } & \multicolumn{2}{|c|}{$\mathrm{A}_{2}$} & \multicolumn{2}{|c|}{$\mathrm{B}_{21}$} & \multicolumn{2}{|c|}{$\mathrm{B}_{22}$} & \multicolumn{2}{|c|}{$\mathrm{B}_{3}$} & \multicolumn{2}{|c|}{ C } \\
\hline & freq. & $\%$ & freq. & $\%$ & freq. & $\%$ & freq. & $\%$ & freq. & $\%$ & freq. & $\%$ \\
\hline es & 242 & 34,3 & 259 & 36,4 & 280 & 35,6 & 252 & 37,8 & 198 & 34,4 & 232 & 41,3 \\
\hline m. $p p$ & 209 & 29,6 & 230 & 32,4 & 221 & 28,1 & 196 & 29,4 & 184 & 31,9 & 172 & 30,6 \\
\hline tu & 221 & 31,3 & 173 & 24,3 & 233 & 29,6 & 185 & 27,8 & 170 & 29,5 . & 122 & 21,7 \\
\hline $\mathbf{z i}$ & 29 & 4,1 & 41 & 5,8 & 47 & 6,0 & 27 & 4,1 & 25 & 4,3 & 32 & 5,7 \\
\hline $\mathrm{ru}$ & - & & 4 & & 1 & & - & & - & & - & \\
\hline an & - & & 1 & & 1 & & - & & - & & - & \\
\hline ci & - & & - & & 1 & & 1 & & - & & - & \\
\hline ep & 1 & 0,7 & 2 & 1,1 & 1 & 0,7 & 2 & 0,9 & - & 0,0 & - & 0,7 \\
\hline gr & 3 & & 1 & & - & & 2 & & - & & - & \\
\hline mo & 1 & & - & & - & & - & & - & & - & \\
\hline $\mathrm{mu}$ & - & & - & & 1 & & 1 & & - & & 4 & \\
\hline Total & 706 & & 711 & & 786 & & 666 & & 577 & & 562 & \\
\hline
\end{tabular}


Quadro 8 - Série Ibitiruna: composição mineralógica do resíduo pesado da areia muito fina.

\begin{tabular}{lrrrrrrrrrrrrrr}
\hline Min. & \multicolumn{2}{c}{ Ap } & \multicolumn{2}{c}{$\mathrm{A}_{2}$} & \multicolumn{2}{c}{$\mathrm{B}_{21}$} & \multicolumn{2}{c}{$\mathrm{B}_{22}$} & \multicolumn{3}{c}{$\mathrm{B}_{3}$} & \multicolumn{2}{c}{$\mathrm{C}$} \\
& freq. & $\%$ & freq. & $\%$ & freq. & $\%$ & freq. & $\%$ & freq. & $\%$ & freq. & $\%$ \\
\hline es & 35 & 4,0 & 32 & 3,7 & 42 & 4,7 & 41 & 4,8 & 47 & 5,0 & 42 & 4,8 \\
m.op & 512 & 58,8 & 482 & 55,5 & 465 & 52,4 & 480 & 55,9 & 502 & 54,5 & 484 & 54,9 \\
tu & 100 & 11,5 & 129 & 14,8 & 132 & 14,9 & 97 & 11,3 & 93 & 10,1 & 79 & 9,0 \\
zi & 184 & 21,1 & 169 & 19,5 & 197 & 22,2 & 188 & 21,9 & 237 & 25,7 & 224 & 25,4 \\
ru & 36 & 4,1 & 51 & 5,9 & 50 & 5,6 & 50 & 5,8 & 41 & 4,5 & 49 & 5,6 \\
ci & - & & 2 & & - & & - & & 1 & & - & \\
du & - & & - & & - & & 1 & & - & - & - & \\
ep & 2 & 0,5 & 2 & 0,7 & 1 & 0,2 & - & 0,2 & - & 0,1 & 1 & 0,3 \\
gr & - & & 1 & & - & & 1 & & - & - & - & \\
mu & 2 & & 1 & & 1 & & - & & - & 2 & \\
\hline Total & 871 & & 869 & & 888 & & 858 & 921 & 881 & \\
\hline
\end{tabular}

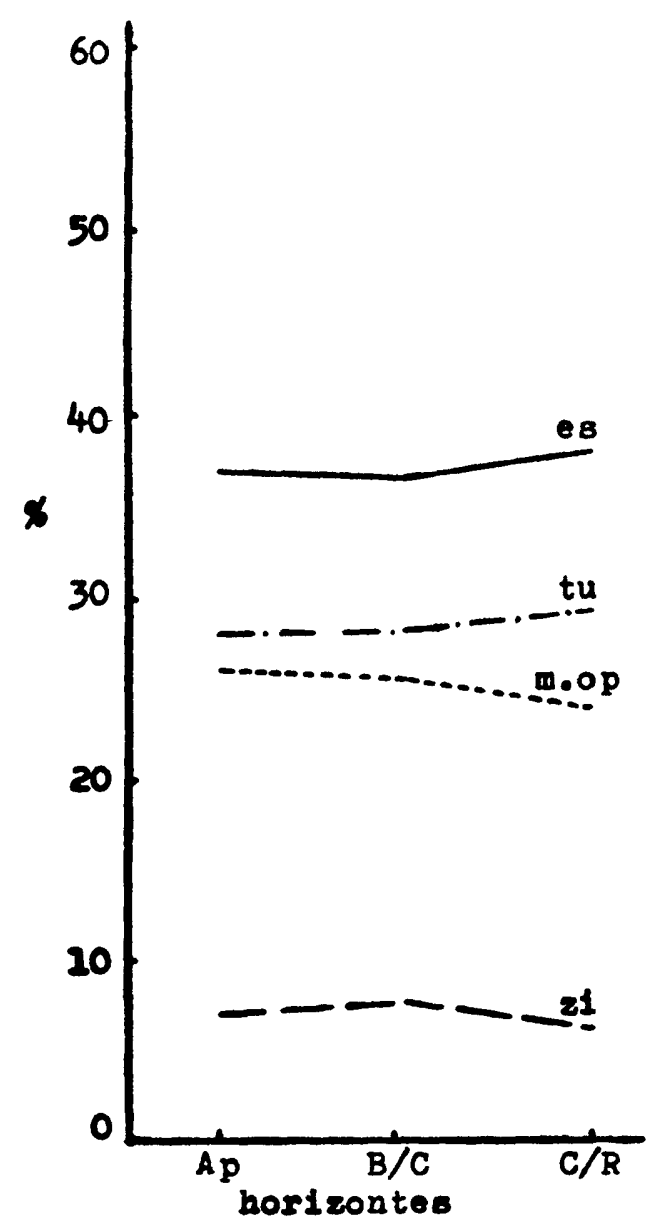

FG. 4 - Série Anhumas: distribuiç̧̃o (\%) dos minerais pesados da areis fina.

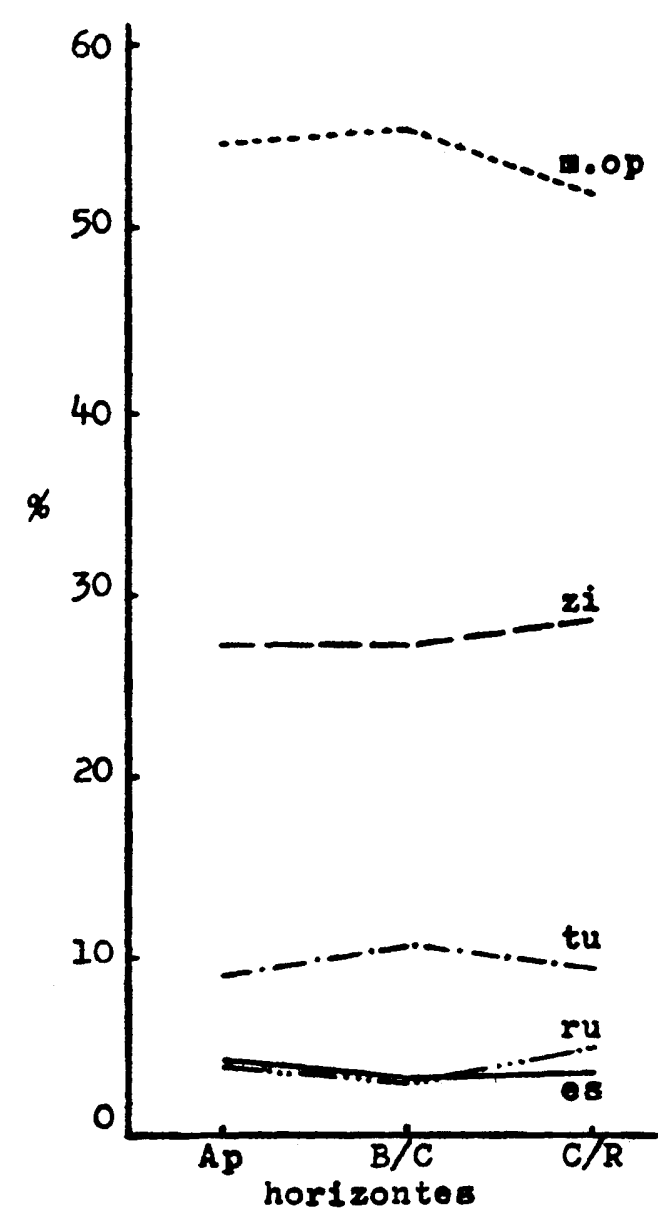

FIG. 5 - Strie Anhumas: distribuiçăo (\%) dos minerais pesados da areia muito fine. 

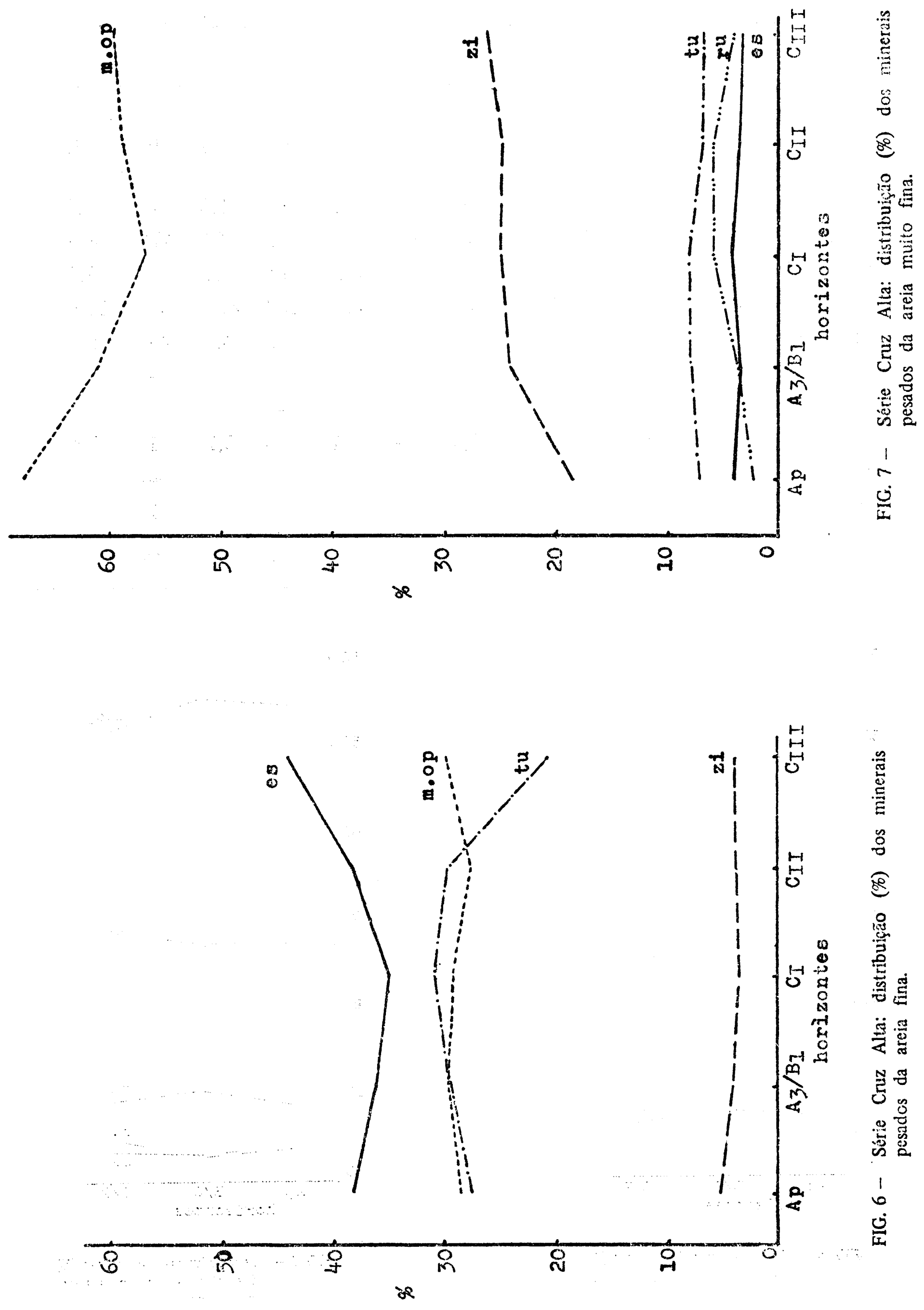

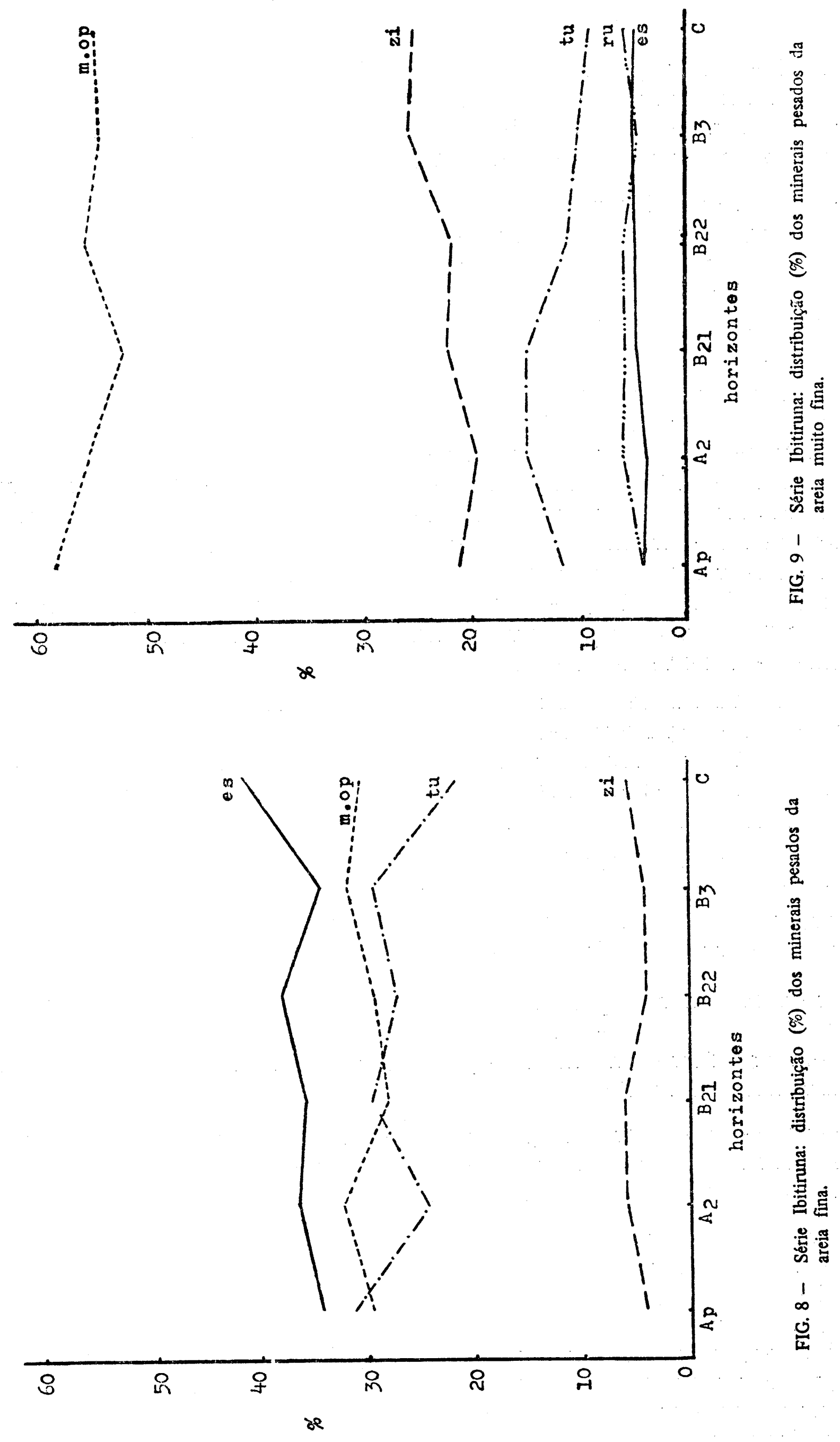
A análise da fração leve revelou predominância acentuada de quartzo em todos os horizontes, constituindo a quase totalidade desta fração, observando-se ocorrência ocasional de feldspatos, notadamente ortoclase. Não foi constatada a presença de nenhum outro mineral leve.

$\mathrm{O}$ estudo do resíduo pesado mostrou a presença de estaurolita, minerais opacos, turmalina e zirconita, constante em todas as amostras, tanto na areia fina como na areia muito fina. Existe acentuada diferença na composição mineralógica das duas frações de areia, no que concerne a concentração daqueles minerais, como é possível observar nas figuras de números 4 a 9 .

$\mathrm{Na}$ areia fina é constante a maior presença de estaurolita, seguida de minerais opacos e turmalina, em quantidade equivalentes e zirconita em menor proporção, nunca atingindo $8 \%$ do total. $\mathrm{Na}$ areia muito fina, esta sequência modifica-se inteiramente, com minerais opacos predominando, constituindo sempre mais de $50 \%$ dos minerais pesados da amostra. 0 teor de zirconita cresce sensívelmente, atingindo mais de $20 \%$. O aumento da concentração de minerais opacos e zirconita se faz em detrimento da concentração de turmalina e, especialmente, estaurolita, que na areia muito fina não atinge valores superiores a $5 \%$. Também, nesta fração granulométrica, é significativa a presença de rutilo, concorrendo em quantidade com estaurolita, embora esteja praticamente ausente na areia fina.

A maior quantidade de minerais opacos, zicornita e rutilo nas frações mais finas de areia é explicada pelo fato de esses minerais serem de tamanho pequeno nas fontes de origem (rochas magnéticas e metamórficas), ao contrário de turmalina e estaurolita, minerais originariamente grandes.

Os minerais opacos são constituídos essencialmente de magnetita e ilmenita. Existe muita dificuldade para se fazer a distinção entre essas duas espécies de minerais, não obstante a magnetita ocorra, frequentemente nas amostras, com faces de octaedro, muito bem desenvolvidas. Com pequena frequência, ocorrem ainda leucoxênio, limonita e pirita.

Os demais minerais presentes, reunidos não atingem em nenhuma amostra, $2 \%$ do total, o que impede tomá-los como caráter diferenciador de séries, embora forneçam informações sobre as rochas que deram origem aos sedimentos da região.

Observa-se que a fração pesada é sempre de composição mineralógica simples, constituída basicamente de poucos minerais, quimicamente estáveis, o que indica elevada maturidade dêsses solos.

A composição mineralógica, pela sua semelhança, não permite distinção entre as três séries de solos, mas mostra que o sedimento que deu origem a esses solos recebeu contribuição tanto de rochas metamórficas como de magmáticas, denunciadas, as primeiras, pela presença de minerais tipicamente metamórficas, como estaurolita, cianita, epídoto, etc., e as segundas, pela presença de zirconita, ilmenita, magnetita, principalmente. E' lícito dizer que a turmalina derivou, provavelmente, de rochas metamórficas, devido à pequena frequência de inclusões encontradas (KRYNINE, 1946). 


\section{Arrodondamento}

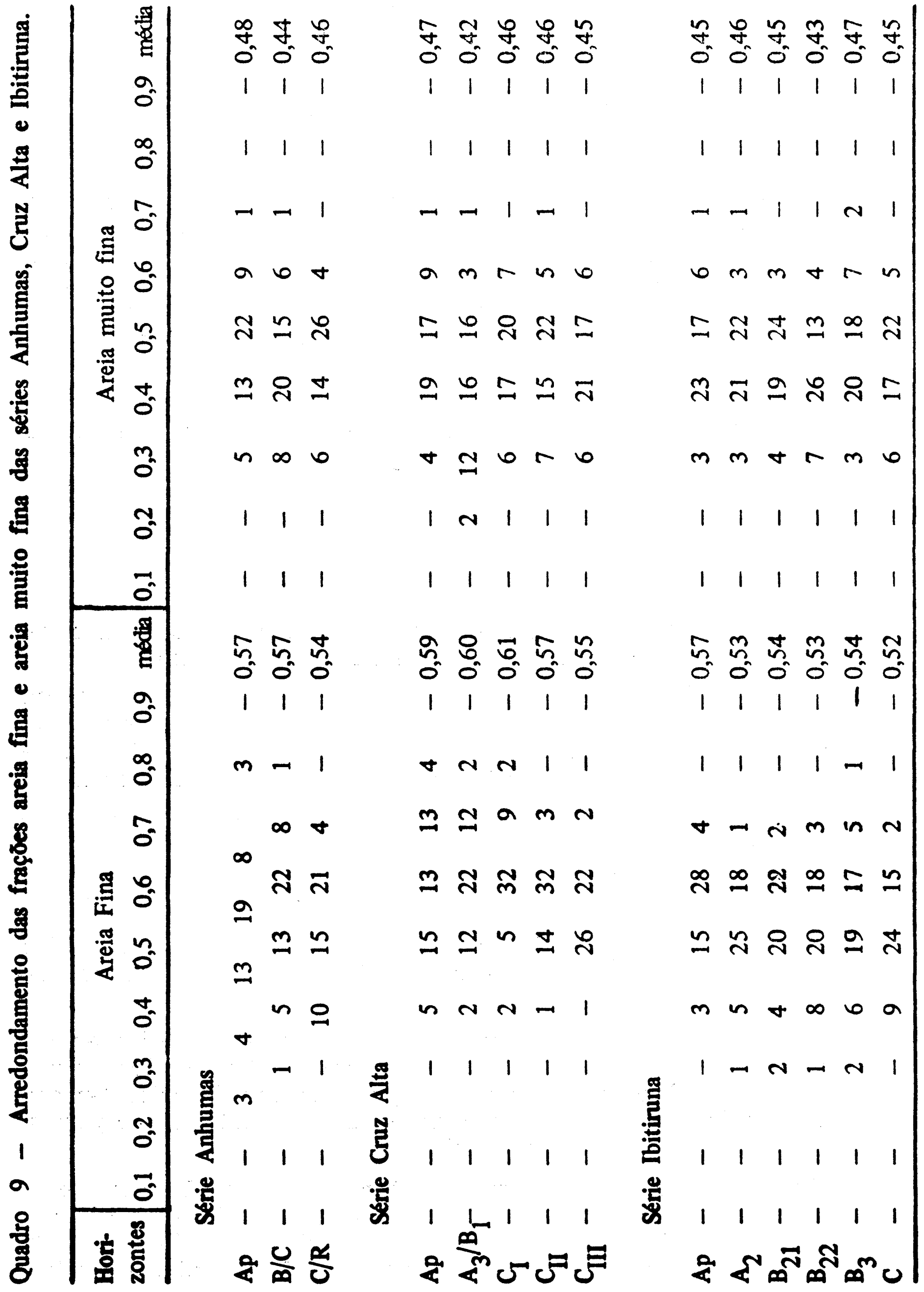


O estudo de arredondamento revelou que são altos os valores encontrados nas três séries, com médias superiores a 0,4. Como era de se esperar, os grânulos da areia muito fina apresentam-se menos arredondados que os da areia fina, porém, ambos, segundo PETTIJOHN (1957), estão situados na classe de grânulos arredondados.

No arenito Botucatu, ALMEIDA (1954) menciona valores de arredondamento entre 0,25 e 0,40 para grânulos com diâmetro inferior a $250 \mu$, classificando-os como subarredondados. CARVALHO (1954) menciona, para a mesma formação, valores de 0,52 a 0,77 , considerando os grânulos arredondados. 0 arredondamento dos solos aqui estudados concorda com o do arenito Botucatu. Valores altos de arredondamento indicam terem os grânulos participado de mais de um ciclo de sedimentação, sofrendo removimentação de sedimentos mais antigos.

Não existe diferença significativa entre as séries, o que impede diferenciá-las através do arredondamento de seus grânules.

\section{CONCLUSOES}

As séries de Anhumas, Cruz Alta e Ibitiruna são constituídas de solos arenosos, com acentuada predominância da areia fina e muito fina.

A composição mineralógica do resíduo pesado dos solos estudados é simples, mostrando minerais essencialmente estáveis. Constituem o resíduo pesado, turmalina, estaurolita, zirconita, minerais opacos (magnetita e ilmenita, principalmente) e, também, rutilo, presente na areia muito fina.

Os valores de arredondamento observados são altos, indicando terem os minerais passado por mais de um ciclo de sedimentação. Este fato, aliado à alta estabilidade dos minerais presentes e à boa seleção granulométrica que as séries exibem, indica elevada maturidade mineralógica desses solos.

As séries apresentam semelhança de granulometria, composição mineralógica e arredondamento, fato que impossibilita, com segurança, sua caracterização individual.

O estudo da granulometria, composição mineralógica e arredondamento permite concluir que a rocha de origem das séries Anhumas, Cruz Alta e Ibitiruna é a mesma. Os resultados obtidos no presente trabalho coincidem com aqueles encontrados por vários autores, no arenito Botucatu, o que permite filiar os solos estudados a essa formação.

Os sedimentos da região em estudo receberam contribuição tanto de rochas metamórficas como de eruptivas, denunciadas as primeiras pela presença de minerais metamórficos, com estaurolita, cianita, epídoto, granada, silimanita e turmalina e os segundos pela presença de zirconita, ilmenita e magnetita, principalmente. 


\section{SUMMARY}

\section{MINERALOGY OF ANHUMAS, CRUZ ALTA AND IBITIRUNA SOIL SERIES}

In this work, the particle size, the mineralogic composition and the roundness of the Anhumas, Cruz Alta and Ibitiruna soil series, from the Piracicaba, São Paulo, Brazil, were studied in their fine sand $(250-105 \mu)$ and very fine sand $(105-53 \mu)$ fractions.

The material that forms these soils is very well selected, in which the fine sand the very fine sand are the dominant fractions, with more than $70 \%$ fo the profiles.

The meniralogic composition shows the presence of stable minerals as tourmaline, magnetite, ilmenite staurolite and zircon. In the very fine sand fraction also occurs rutile. The roundness is high in the studied material, what must be indicating that it was present in more of one sedimentations cycle.

The obtained data permit conclude that these three soil series are formed from material of the same origin, which is very well selected and with great maturity. It is impossible the individual identification of each soil serie by the studies that were developped in this work. By the other hand, it is possible to conclude that these soils are formed from Botucatu Sandstone.

\section{LITERATURA CITADA}

ALMEIDA, F. F. M. e BARBOSA, O., 1953 - Geologia das Quadriculas de Piracicaba e Rio Claro, Estado de São Paulo. Div. Geol. e Min., DNPM, Bol. 143. 96 pp.

ALMEIDA, F. F. M., 1954 - Botucatu, um Deserto Triássico da América do Sul. Notas Preliminares e Estudos, DNPM, 86. 16 pp.

AMARAL, S. E., 1955 - Sedimentologia e Geologia das Camadas Perfuradas na Região da Foz do Rio Amazonas. Fac. Fil. Ciên. Let. USP, Bol. 192, Geol. 12. $93 \mathrm{pp}$.

CARVALHO, A. M V, 1954 - Contribuição ao Estado Petrográfico do Arenito Botucatu no Estado de São Paulo .Bol. Soc. Bras. Geol. 3 (1) : 51-72.

COMISSÃO DE SOLOS DO C. N. E. P. A., 1960 - Levantamento de Reconhecimento dos Solos do Estado de São Paulo. Bol. Serv. Nac. Pes. Agr. 12: 634 pp.

JEFFRIES, C. D., 1937 - The Mineralogical Composition of the Very Fine Sands of Sone Pennsylvania Soils. Soil Sci . 43:357-366.

JEFFRIES, C. D. and JACKSON, M. L., 1949 - Mineralogical Analysis of Soils. Soil Sci. 68: 57-73.

KILMER, V. J. and ALEXANDER, L. T., 1949 -- Method of Making Mechanical Analysis of Soils. Soil Sci. 68: 15-26.

KRUMBEIN, W. C. and PETTIJOHN, F. J., 1938 - Manual of Sedimentary Petrography. Appleton-Century-Grofts, Inc. New York, USA. 549 pp.

KRUMBIEN, W. C., 1941 - The Effects of Abrasion on the Size, Shape and Roundness of Rock Fragments. J. Geol. 49 (5): 449-482.

KRYNINE, P. D., 1946 - The Tourmaline Group in Sediments. J. Geol. 54 (2) : 65-87. 
MELFI, A. J., GIRARDI, V. A. V. e MONIZ, A C , 1966 - Mineralogia dos Solos da Estação Experimental "Theodureto de Camargo", em Campinas. Bragantia 25: 9-30.

MEZZALIRA, S., 1965 - Descrição Geológica e Geográfica das Folhas de Piracicaba e São Carlos, SP. Inst. Geogr. Geol. Bol. 43. 41 pp.

PETTIJOHN, F. J., 1957 - Sedimentary Rocks Harper and Brothers. New York, USA, 2." ed. $718 \mathrm{pp}$.

RANZANI, G., FREIRE, O. e KINJO T., 1966 - Carta de Solos do Municipio de Piracicaba. Centro de Estudos de Solos, ESALQ, USP .(mimeografado). 85 pp.

ROSENFELD M. A. and GRIFFETHS, J. C., 1953 - An Experimental Test of Visual Comparison Technique in Estimating Two Dimensional Sphericity and Roundness of Quartz Grains. Am. J. Sci. 251: 553-585.

TWENHOFEL, W. H. and TYLER, S. A., 1941 - Methods of Study of Sediments. McGraw-Hill Book Co., Inc. New York, USA. 183 pp. 